\title{
NOTAS SOBRE GRABADOS Y PINTURAS ASOCIADOS A NECROPOLIS COLECTIVAS CALCOLITICAS: LOS CONJUNTOS DE LAS CUEVAS DE LOS ENEBRALEJOS Y DE LA VAQUERA (SEGOVIA)
}

\author{
POR \\ LUCIANO JOSE MUNICIO GONZALEZ (*) \\ ALONSO ZAMORA CANELLADA (*)
}

\begin{abstract}
RESUMEN Recientes descubrimientos de grabados y pinturas en la Cueva de La Vaquera permiten hacer varias reflexiones sobre el carácter y significado de estas manifestaciones artísticas, vinculadas a los enterramientos colectivos del inicio de la metalurgia en el Sudeste de la Cuenca del Duero.

ABSTRACT Recent discoveries of parietal engravings and paintings at "Cueva de La Vaquera» permit us to consider the character and meaning of these artistic expressions, which are associated with the collective burials of the earliest metallurgical horizon of the southeast of the Duero basin.
\end{abstract}

Palabras clave Grabados y pinturas. Necrópolis colectivas calcolíticas. Segovia.

En los esquemas, en ocasiones excesivamente rígidos, del estudio del arte rupestre de nuestra Península, raras veces ha encontrado cabida el análisis de unas manifestaciones artísticas -si es que puede aplicárseles en rigor tal calificativo-, como son los grabados y pinturas realizados en cuevas, de cronología postpaleolítica y más concretamente, vinculados al inicio de la metalurgia. Tales representaciones parecen encontrar una concreción particular en la red de cuevas de la orla montañosa oriental y sudoriental de la Cuenca del Duero, desde los conjuntos de la Galería del Sílex de Atapuerca hasta las cuevas sepulcrales del piedemonte del Sistema Central, en tierras segovianas.

Aunque innegablemente vinculados al fenómeno del arte esquemático postpaleolítico, quizás constituyan la muestra menos atrayente, en lo que a espectacularidad se refiere, dentro de este campo, y quizás del repertorio de nuestro arte prehistórico. Probablemente este hecho, unido a la proximidad geográfica de los grandes conjuntos de arte esquemático, sea la causa por la que con frecuencia han sido relegados a un segundo plano por los investigadores, aunque no por esos motivos disminuya un ápice el interés en cuanto al estudio de sus representaciones y de su significación intrínseca.

(') Arqueólogo Territorial de Segovia.

(“) Director del Museo Provincial de Segovia. 
Son varios los motivos que ahora nos impulsan a escribir estas lineas, pero ei principal de ellos es, sin duda, haber sabido que el presente numero de Trabajos de Prehistoria se dedicaria a la memoria de Fernando Piñón. Ello nos animó a dar a conocer los preliminares de un trabajo que se encuentra aún en plena elaboración, pero en cuya génesis Fernando tuvo un destacado papel, desde que a comienzos de 1985 conoció el conjunto de grabados y pinturas de Prádena, cuyo estudio acometió de inmediato con uno de los firmantes (L. M. G.), con la entrega absoluta y la visión precisa y critica que siempre le caracterizaron.

Cuando ese primer estudio se encuentra en fase avanzada de su desarrollo, el descubrimiento $-o$, mejor dicho, el re-descubrimiento- del impresionante conjunto de grabados de la cueva de La Vaquera, en el curso de una reciente campaña de excavaciones (1), nos proporciona, aún en los comienzos de su análisis, la mejor ocasión de rendir nuestro particular homenaje al amigo que en todo momento supo orientarnos en el difícil terreno del estudio del arte prehistórico.

Poco es lo que la bibliografía arqueológica dice a propósito de estos conjuntos. En un rápido repaso, y limitándonos al sector sudoriental de la Cuenca del Duero, área a la que voluntariamente nos limitamos, hay que citar en primer lugar las noticias concretas sobre los conjuntos grabados de la cueva de Los Enebralejos (Prádena, Segovia) (Cabellos, Gómez, Llobet, 1967) y de la también segoviana cueva de La Vaquera (Torreiglesias) (Lemus, Alvarez, 1967). Más recientemente, la información sobre la cueva de San Bartalomé de Ucero (García-Soto, Moure, 1984) y, fuera de la zona a la que pretendemos ceñirnos, el estudio de Apellániz y Uribarri sobre las representaciones del denominado "Santuario" de la Galería del Sílex de Atapuerca (Apellániz, Uribarri, 1976), punto al que necesariamente hay que volver la vista al abordar el análisis de estas manifestaciones, componen el exiguo repertorio de datos recientes sobre este tema. Quizás, y fuera también de nuestra zona de referencia, deberíamos incluir las representaciones de la cueva de Kaite, en el complejo de Ojo Guareña, aunque sus características se alejan, en cierto modo, de las que encontramos en el sector sudoriental de la Cuenca del Duero.

Aun cuando el estudio que dio a conocer el conjunto de Los Enebralejos presenta determinados elementos extraños, sobre todo en lo que se refiere a interpretación global de las representaciones o a comentarios poco acertados en cuanto a explicación y significado de diversos motivos, lo cierto es que es posible encontrar algunas ideas muy cercanas a las hipótesis que personalmente defendemos. Así, los autores se plantean dudas sobre el significado de los grabados, entendidos como «...representaciones de entes definidos materialmente", o bien como una "...manifestación [...] relacionada con el carácter funerario de la cueva" (Cabellos, Gómez, Llobet, 1967: 167), situación esta última que, como veremos más adelante, presenta bastante visos de verosimilitud. No es aceptable, sin embargo, la cronología propuesta de Bronce Final, puesto que todo el repertorio de cultura material de Enebralejos se sitúa entre el Calcolítico y, en el mejor de los casos, los inicios del Bronce Antiguo (Municio, Piñón, e. p.).

Como en el caso anterior, la nota de Lemus y Alvarez sobre los grabados de La Vaquera adolece de una serie de inexactitudes y argumentaciones poco afortunadas a la hora de buscar interpretaciones y significado de los motivos, situación en la que en ocasiones se aprecia, al igual que en el estudio de Enebralejos, una imaginación un tanto desbordada.

En cambio, no debe perderse de vista la adscripción «eneolítica" del conjunto, «...entre los años 3000 al 1500 a. C." (Lemus, Alvarez, 1967: 163), bastante aproximada, desde nuestro punto de vista, aun con la amplitud de fechas señalada.

Más interesantes resultan algunas opiniones sobre el carácter de los grabados. En opinión de estos autores, "...se trata de simbolos, más que de imágenes" (Ibid.: 163), a los que encuentran una motivación especial, puesto que consideran que "...es precisamente el culto a los muertos 'el que' ha grabado estos garabatos (Ibid.: 164). Después incidiremos en estas cuestiones.

En el caso de la Galería del Sílex, la interpretación de Apellániz y Uribarri dota de un carácter

(1) Incluida en el Programa de Excavaciones de Urgencia de la Junta de Castilla y León, ante la perspectiva de construcción de un embalse que afectará seriamente al yacimiento, esta primera campaña ha sido dirigida por D. Juan Carlos Iglesias Martínez. 
religioso a los motivos en ella documentados, punto de vista que queda reflejado ya en la calificación del yacimiento y el conjunto de representaciones plásticas como "Santuario", donde el carácter artístico o estético de los motivos queda disminuido por "una expresión de concepciones simbólicas $y$ religiosas por medios plásticos" (Apellániz, Uribarri, 1976: 179).

Es discutible la ubicación cronológica y cultural del yacimiento artistico, que se orienta hacia fases avanzadas del Bronce. El carácter de los materiales recuperados en la Galeria del Silex, mejor perfilado desde la publicación del conjunto de cerámicas de superficie (Apellániz, Domingo, 1987), nos lleva a contemplar fechas anteriores, que englobarían - siempre a partir de comparaciones de elementos materiales - una teórica secuencia del Neolítico a los inicios del Bronce, con pocas posibilidades de justificar la datación precisa de los grabados.

El único caso en que ello es posible se refiere al vaso con decoración de cordones que reproduce una de las figuras antropomorfas del Gran Panel (Delibes, 1985: 27; Apellániz, Domingo, 1987). Aun siendo conscientes de los riesgos que afirmaciones de este tipo entrañan, parece conveniente apuntar que los caracteres formales y decorativos de dicho vaso -excepción hecha de la figura antropomorfa - se encuentran perfectamente documentados entre los característicos de la cueva de Los Enebralejos, donde las particulares condiciones del yacimiento arqueológico nos permiten hablar de un conjunto cerrado atribuible, como más arriba decíamos, a los primeros momentos de la metalurgia, por lo que quizás, en este caso, dispongamos de un indicador cultural fiable (Municio, 1988: 314).

La información más reciente que hemos podido manejar sobre el tema que nos ocupa, elaborada por García-Soto y Moure a partir de los grabados de la cueva de San Bartolomé de Ucero, establece una zona definida por los rebordes montañosos de la cuenca del Duero como área de dispersión de estos grabados.

Las referencias cronológicas que se aportan llevan, una vez más, a los finales de la Edad del Bronce, argumentadas a partir de los datos de los yacimientos burgaleses de Ojo Guareña (Galería de la Fuente) y Atapuerca (García-Soto, Moure, 1984: Jordá, 1968: Apellániz, Uribarri, 1976). Más adelante entraremos en estas cuestiones, a la vista de los nuevos datos de que disponemos procedentes de los yacimientos segovianos.

A partir de este momento no pretendemos, en absoluto, dar ni siquiera una visión de conjunto de las representaciones de las cuevas segovianas citadas. El estudio de Los Enebralejos, unido al recientemente iniciado de La Vaquera -en estos momentos, en fase de topografía de detalle y documentación fotográfica y fotogramétrica-, serán publicados conjuntamente con la mayor rapidez posible, dentro de las limitaciones que impone la complejidad del análisis de estos grupos plásticos. Tan sólo queremos dejar constancia de una serie de reflexiones surgidas a propósito de ambos conjuntos, a partir de las cuales hemos orientado nuestro trabajo sobre los mismos.

Las representaciones de La Vaquera y su vinculación con el yacimiento arqueológico han servido, incluso a partir de una visión superficial, para confirmar algunas de las hipótesis que el conjunto de Prádena nos sugirió en su momento. En este sentido se orientan las presentes líneas, que -insistimos en ello- no deben entenderse sino como producto de unas primeras reflexiones sobre el tema.

Prescindiremos intencionadamente de toda descripción pormenorizada de motivos, agrupaciones, etc. -quede ello para el estudio definitivo de ambos yacimientos-, señalando tan sólo la proliferación de parrillas, zig-zags (sencillos o múltiples), tectiformes y "marañas» de trazos lineales simples, a modo de 'macarroni', junto con una menor representación de arborescentes, pectiniformes y contados ejemplos de motivos antropomorfos y zoomorfos (Municio, Piñón, 1988). Las representaciones de las cuevas segovianas no se alejan de las contrastadas en Atapuerca o San Bartolomé de Ucero y su temática, como recientemente se ha dicho, aun siendo próxima a los repertorios, digamos, "clásicos" del arte rupestre esquemático, presenta ciertas "...peculiaridades que las confieren un carácter especiabs (García-Soto, Moure, 1984: 159).

En lo referente a técnicas, ambos yacimientos presentan dos resoluciones distintas en sus grabados, ejecutados bien con un instrumento cortante, que se manifiesta en un grabado fino y 
profundo con sección en $\mathrm{V}$, bien con la ayuda de elementos de origen vegetal, cuyo empleo se manifiesta en surcos anchos y de escasa profundidad en cuyo interior se identifican con total nitidez las improntas de las fibras vegetales.

Esta diversidad en cuanto a técnicas queda patente en otros estudios y yacimientos, donde parece una constante. En Ucero se identifican *...dos grupos de acuerdo con la profundidad de la incision" (Garcia-Soto, Moure, 1984: 156), mientras que en Prádena las diferentes técnicas se intuian ya en el escrito de Cabellos et al., aunque se manifestaba de forma bastante imprecisa (Cabellos, Gómez, Llobet, 1967: 166). Podemos ver una situación parecida en Atapuerca, donde se identifican grabados de diferente anchura y profundidad y, en especial, una "...punta seca ancha $y$ astillada que ha dejado un rastro de múltiples estriasn (Apellániz, Uribarri, 1976: 72 y fig. 30) que podría identificarse con el último tipo de grabado al que hacemos alusión.

Las primeras impresiones sobre el conjunto de La Vaquera pueden confirmar lo que en su día apuntábamos a partir de los paneles de Enebralejos, en el sentido de que los motivos pintados en negro en este último yacimiento se infraponían a todo tipo de grabados en los lugares donde coexistian ambas técnicas, lo que proporciona de entrada un buen indicador en cuanto a cronología relativa para los dos yacimientos, si bien no ha sido posible, por el momento, inferir ninguna connotación cultural ni de otro tipo a partir de esta comprobación.

- En el caso de Prádena (el pésimo estado de conservación de las pinturas descubiertas en La Vaquera no ha permitido aún la comprobación en este yacimiento), los motivos pintados encuentran replicas similares entre los grabados. La temática, en el caso de las pinturas, parece reducirse a algunos zig-zags simples y dobles, unidos en este último caso por uno de los extremos -exceptuando el plafón con motivos antropomorfos y zoomorfos, por su excepcionalidad dentro del conjunto, y que ha sido dado a conocer en otro lugar (Municio, Piñón, e. p.). Este tipo de figura puede identificarse como uno de los temas más característicos de ambos yacimientos, hallándose presente en buena parte de los paneles decorados en asociación con el resto de los motivos y con una particular incidencia de los zig-zags simples en el caso de La Vaquera.

El principal problema que plantea este tipo de manifestaciones plásticas, al margen de su significado, se refiere a su correcta localización cronológica y cultural. Prádena, en este sentido, puede despejar algunos interrogantes, puesto que el yacimiento arqueológico que encierra la cueva de Los Enebralejos debe considerarse como un conjunto cerrado. Tras las diversas fases de realización de enterramientos, la cueva queda sin utilización humana aparente, hasta su redescubrimiento en 1932, dada la ausencia total de elementos que nos permitan intuir una ocupación posterior al mundo de los enterramientos colectivos calcolíticos y -en el supuesto más favorable para el establecimiento de una cronología amplia - de los primeros compases del Bronce Antiguo.

Disponemos ya de dos fechas $\mathrm{C} 14$ obtenidas en este yacimiento, una de las cuales se relaciona con la primera fase de utilización de una de sus salas, y que arroja una fecha de $4070 \pm 60=2120$ a. C. (CSIC-724). El nivel inmediatamente superior a éste fue fechado por el mismo procedimiento en $3800 \pm 60=1850$ a. C. (CSIC-723), faltándonos por el momento una referencia de las capas más superficiales del yacimiento, donde una intensa alteración de los niveles por causas humanas y por la propia dinámica interna de la gruta han impedido, hasta el momento, la obtención de muestras con una mínima garantía de fiabilidad.

Los datos que nos permiten relacionar las manifestaciones «artísticas" con el yacimiento arqueológico son menos precisos, aunque el carácter de conjunto cerrado que antes atribuíamos al yacimiento nos hace suponer una vinculación del «arte» a la utilización de la cueva como espacio sepulcral. En este sentido, nos ha parecido siempre significativa la distribución paralela de motivos grabados y zonas de enterramiento, que alcanza su grado máximo en el enterramiento aislado en una de las galerías secundarias de Enebralejos (Municio, Piñón, 1988), donde la relación enterramiento-grabados/pinturas se ve potenciada por el aislamiento y la precisa delimitación espacial que proporciona la misma galería. Es conveniente recordar, una vez más, las impresiones de los primeros investigadores de estos yacimientos, relacionando el "arte» con el carácter funerario 
de los yacimientos y un posible culto a los muertos (Cabellos, Gómez, Llobet, 1967: 167; Lemus, Alvarez, 1967: 164).

La cueva de la Vaquera facilita ahora nuevos argumentos para apoyar esta hipótesis. Aunque el uso continuado del lugar a lo largo de cuatro milenios de utilización humana y la más reciente labor destructiva de los numerosos excavadores clandestinos que han visitado el yacimiento nos hacen partir de una situación poco grata, aún es posible determinar el espacio utilizado como necrópolis de inhumación colectiva durante el Calcolítico, puesto que el "trabajo" de los furtivos se ha limitado en todos los casos al espolio de ajuares de estas tumbas, cuyos restos óseos quedaron depositados in situ a lo largo de la galería principal con los escasos restos de ajuares despreciados por los saqueadores.

De esta forma, y ya desde los primeros momentos, nos ha sido posible establecer la correlación precisa de espacio sepulcral y aparición de paneles decorados, ya intuida en el yacimiento de Prádena.

Parece, pues, que el estudio de estas particulares manifestaciones "artísticas» debe emprenderse desde la perspectiva de un warten relacionado con el mundo funerario, situación que puede explicar, además, el carácter de los paneles, algunos de los cuales constituyen verdaderos palimsestos en los que una y otra vez se plasman similares motivos, llegando a producir una sensación de auténtica mezcolanza, por la reiteración y superposición de figuras. Esta circunstancia queda reflejada de forma bastante expresiva por Cabellos et al., hablando del aspecto de los grabados, al anotar que el "artista" «...no tiene ningún impedimento en grabar sobre lo que ya antes había grabado, produciendo una desagradable sensación de lio y confusión (Cabellos, Gómez, Llobet, 1967: 167).

Cuando publicábamos la primera nota sobre los grabados de Prádena (Municio, Piñón, 1988), nos referíamos a esta situación como producto de una intención deliberada que, incluso, llegábamos a entender como desprovista de cualquier motivación de tipo estético $-\mathrm{y}$, así, poníamos en cierta manera en tela de juicio el carácter estrictamente artístico de estas representaciones-, aunque en modo alguno pueden desprenderse los grabados de una motivación expresiva clara (Apellániz, Uribarri, 1976: 179). El mismo carácter acumulativo de las necrópolis colectivas de la zona se traspasaría, pues, a las representaciones parietales, como consecuencia lógica del vínculo existente entre ambas manifestaciones.

No hay duda de que los motivos rupestres que ahora nos ocupan se inscriben en el mundo de las representaciones artísticas de nuestra Prehistoria. Ahora bien, valorar el peso específico de su componente puramente artística, y de la que podría calificarse como simbólica, etc., es ya algo que se prestaría a una interminable discusión.

Desde nuestro punto de vista, y como ya expusimos una vez, nos inclinamos por ver en ellos elementos definidores de espacios concretos y con una función particular o, como entonces escribíamos, testimonios de "...una demarcación topográfica de ámbitos simbólicos" (Municio, Piñón, 1988). Creemos, a partir de los ejemplos proporcionados por las cuevas segovianas, que es bastante acertado aceptar el carácter de estos grabados y pinturas como señalizadores de un espacio sepulcral. Al menos, desde una óptica actual, sin discutir por ello que pueda tratarse de testigos de algún tipo de manifestación espiritual relacionada con la práctica de enterramientos. El hecho es que, hoy por hoy, y en el sector geográfico al que al principio aludíamos, se convierten en claros indicadores de espacios funerarios. Entrar en consideraciones sobre su significado último o los motivos que impulsaron a su realización es algo para lo que se cuenta con poca o ninguna base, situándonos a la vez en un terreno muy resbaladizo, al referirse a cuestiones que, si nuestras suposiciones son correctas, tocarían de lleno el mundo de las creencias, pocas veces accesible con claridad a partir de los datos puramente arqueológicos. 


\section{BIBLIOGRAFIA}

Apellániz Castroviejo, J. M.: Uribarri Angulo, J. L. (1976): «Estudio sobre Atapuerca (Burgos). I.- El Santuario de la Galería del Silexw. Cuadernos de Arqueologia de Deusto. 5. Bilbao.

Apellaniz Castroviejo, J. M. y Domingo MenA, S. (1987): „Estudios sobre Atapuerca (Burgos). II.- Los materiales de superficie del Santuario de la Galería del Sílex». Cuadernos de Arqueología de Deusto. 10. Bilbao.

Burdiel de las Heras, I. (1964): "Trabajos de reconocimiento de la cueva de Prádena*. Noticiario Arqueológico Hispánico. VI: 100-102. Madrid.

Cabellos, E., Gómfz, E. y Llobet, A. (1967): "Grabados esquemáticos de la cueva de Prádena". Actas del IX Congreso Nacional de Arqueología (Valladolid, 1965): 166-174. Zaragoza.

Delibes de CAStro, G. (1985): «El Neoliticon. En «Historia de Castilla y León. I- La Prehistoria del Valle del Duero». Ambito Ediciones, S. A.: 22-35. Valladolid.

García.Soto, E. y Moure, J. A. (1984): «Los grabados esquemáticos de San Bartolomé de Ucero (Soria)». Actas del Primer Symposium de Arqueologia Soriana: 151-167. Soria.

JORDÁ CERDÁ, F. (1968): «Nuevas representaciones rupestres de Ojo Guareña (Burgos)». Zephyrus, XIX-XX: 61-71. Salamanca.

Lemus Chavarri, C. y Alvarez Redondo, J. L. (1967): «Grabados eneolíticos de la cueva de la Fuente Dura (Losana de Pirón, Segovia)n. Actas del IX Congreso Nacional de Arqueologia (Valladolid, 1965): $162-165$. Zaragoza.

Municio González, L. (1988): «El Neolítico en la Meseta Central española». En P. López (Coord.): «El Neolitico en España». Ed. Cátedra, S. A.: 299-327. Madrid.

Municio González, L. y Piń́n VARela, F. (1988): „Programa de documentación y estudio de la cueva de Los Enebralejos (Prádena, Segovia)». Actas del I Congreso Internacional de Arte Rupestre (Zaragoza-Caspe, 1985). Zaragoza.

- (e. p.): «La cueva de Los Enebralejos (Prádena, Segovia)». Nvmantia, 3. Valladolid, en prensa.

Ruiz ARgIles, V. (1976): «Cueva y poblado de Los Enebralejos (Prádena, Segovia)». Noticiario Arqueológico Hispánico, Prehistoria, VI: 271-280. Madrid.

URIBARRI, J. L. y Liz, C. (1973): «El arte rupestre de Ojo Guareña. La Cueva de Kaiten. Trabajos de Prehistoria, 30: 69. Madrid.

Zamora Canellada, A. (1976): «Excavaciones de la cueva de La Vaquera, Torreiglesias. Segovia (Edad del Bronce). Excma. Diputación Provincial. Segovia. 


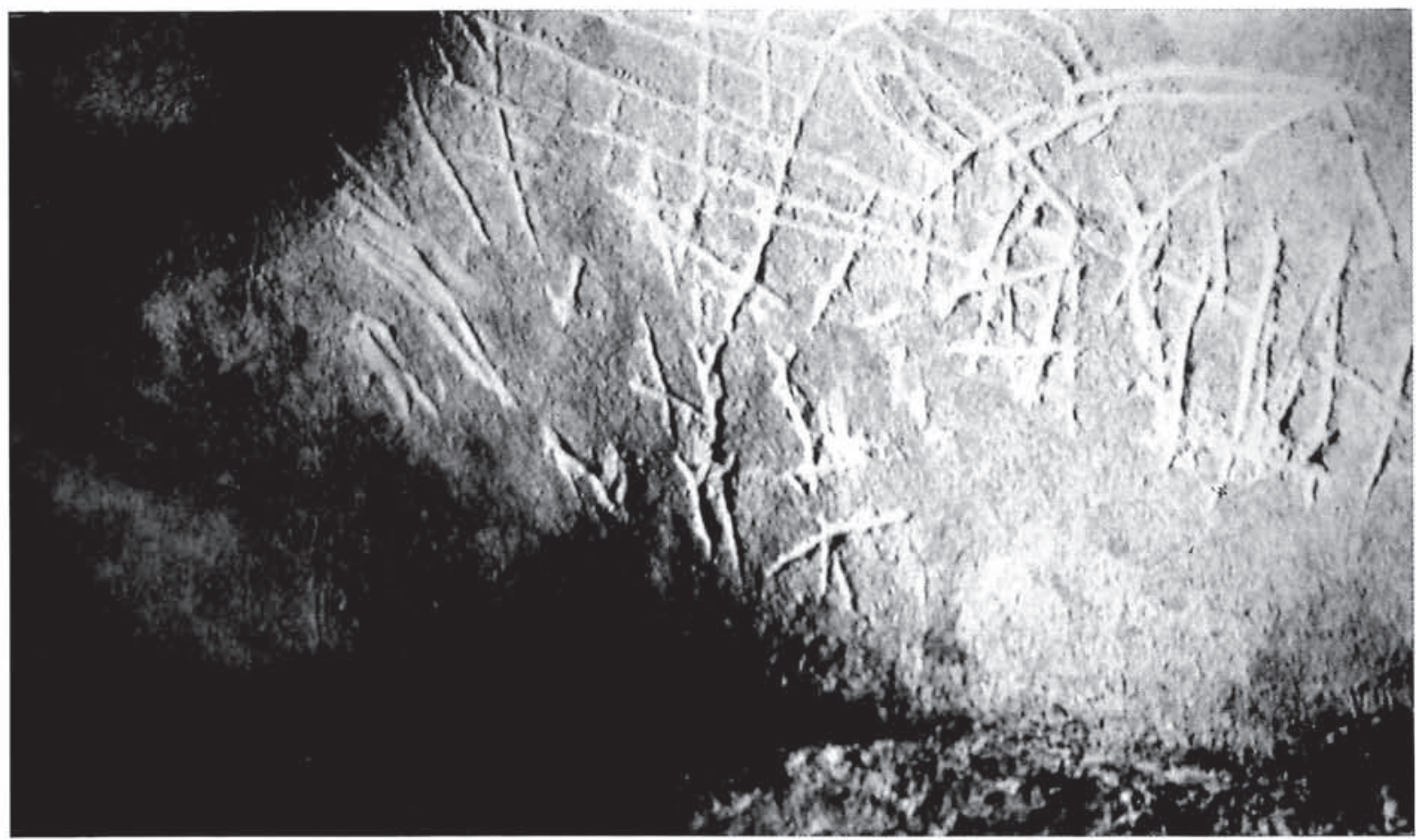

Aspecto parcial de uno de los paneles grabados de Los Enebralejos (Foto: Latova/Otero/Ripoll).

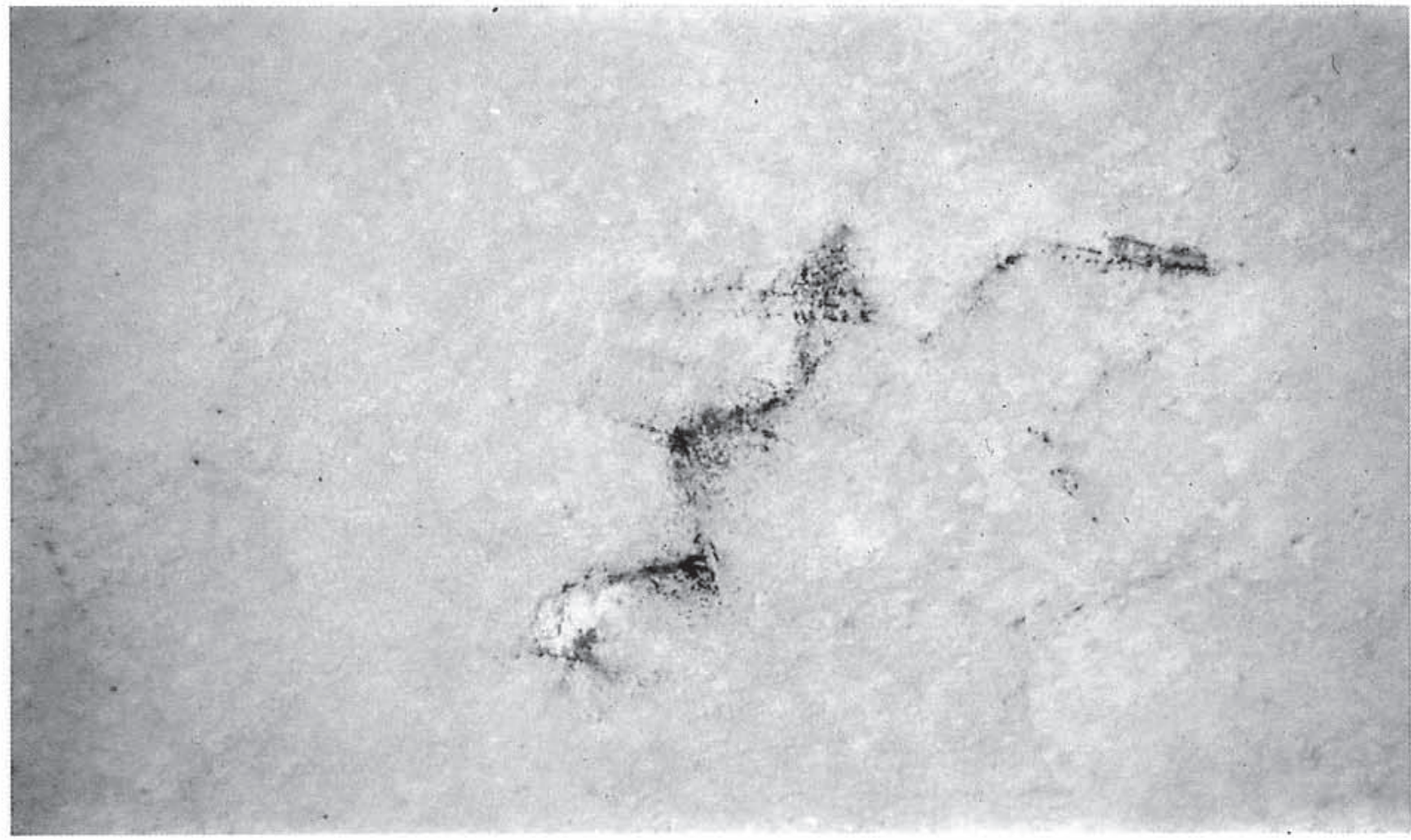

Zig-zag doble pintado en negro. Cueva de Los Enebralejos (Foto: Latova/Otero/Ripoll). 

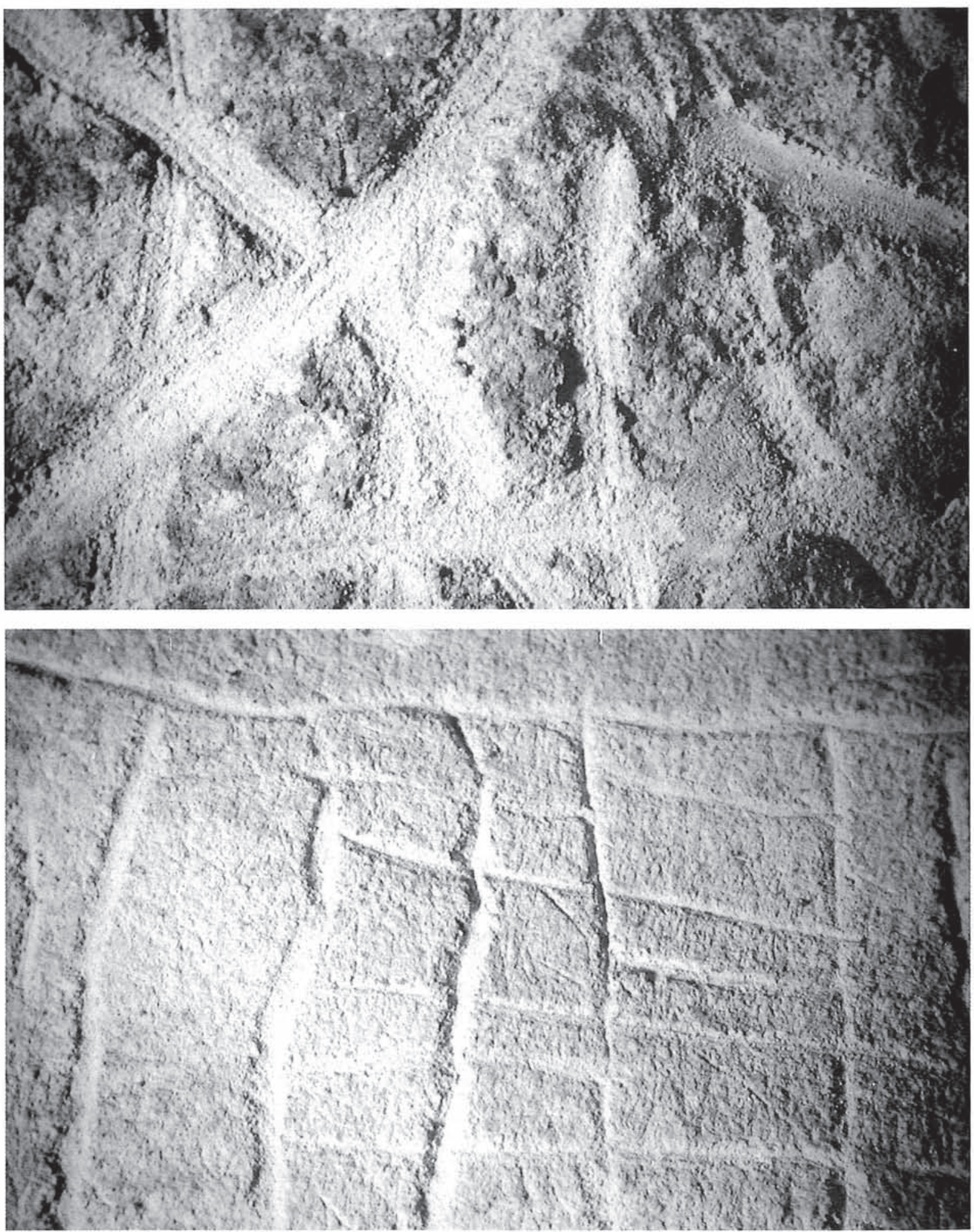

Detalles de las dos técnicas de grabados identificadas en Los Enebralejos y La Vaquera. (Fotos: Latova / Otero / Ripoll. 